\title{
Analysis of Vehicle Crash Injury-Severity in a Superhighway: A Markovian Approach
}

\author{
John Carlo F. Marquez, Darwin Joseph B. Ronquillo, \\ Noime B. Fernandez and Venusmar C. Quevedo \\ Industrial Engineering Department Adamson University, Manila, Philippines 1000 \\ E-mail: \{jcmarquez000; darwinjosephronquillo; vcquevedo\}@gmail.com; \\ fernandez.noime@yahoo.com
}

Received 17 November 2016; Accepted 15 January 2017; Publication 14 February 2017

\begin{abstract}
According to the World Health Organization (WHO), road traffic accidents is one of the top causes of death worldwide that claims roughly 1.3 million lives annually. In the Philippines, the Philippine National Police-Highway Patrol Group (PNP-HPG) data showed that there were 15,572 road accidents nationwide for the whole of 2014, with 1,252 persons killed and 9,347 others injured. A comprehensive study was conducted which aims to determine which road traffic accident factors are significant with the severity of road traffic accidents, determine which factors are significant per level of severity, and determine the human factors associated in the occurrence of road traffic accidents that are significant with the levels of severity. Markov Chain Switching Approach enables to determine the probability of occurrence of road traffic accidents and the significant factors that affects the severity of a road traffic accident since it takes into consideration the heterogeneity of the variables and the different time-varying and time-dependent constraints which are not considered by other regression techniques used in road traffic accidents severity literature.
\end{abstract}

Keywords: Markov Chain Switching Model, Road Traffic Accidents, Injury Severity, Commonwealth Avenue.

Journal of Industrial Engineering and Management Science, Vol. 1, 33-48.

doi: 10.13052/jiems2446-1822.2017.003

(c) 2017 River Publishers. All rights reserved. 


\section{Introduction}

Road traffic is one of the most common causes of death worldwide. In 2013, approximately 1.24 million people died from road traffic accidents, which is one on the reason it claimed the ninth spot on the list of the World's Health Organization's (WHO) Top Ten Causes of Death. Road traffic accidents is the only cause of death that is not associated with any human diseases. In 2012, road traffic accidents claimed nearly 3,500 lives each day.

In the Philippines, in a report from the Metropolitan Manila Development Authority (MMDA), there were 82,757 road accidents that were recorded in Metro Manila alone, an average of 227 accidents per day. Of these, 412 were fatal and the victims were mostly pedestrians. According to the status report published by the Department of Health (DOH), road accidents rank fourth in the top causes of death in the country in 2013. This is only the cause of death that is not health-related issue. Being ranked as fourth in the top causes of death is very alarming since there are many aggressive campaigns, strict ordinances, and other similar efforts by the MMDA, Land Transportation Office (LTO), and Local Government Units (LGUs) to increase the awareness of the different road accidents and the preventive measures to minimize their occurrences. However, instead of decreasing frequency of accidents, it is alarming that this is gradually increasing every year.

This study was conducted in Commonwealth Avenue, the so called "Killer Hi-Way of Metro Manila", to identify 1) the significant factors that affect the severity of crash injury accidents 2 ) the significant factors per level of severity of road traffic accidents, and 3) the critical driver error/s related to the level of severity of crash and 4) other factors affecting the casualty of having road accidents.

\section{Review of Related Literature and Studies}

\subsection{Road Traffic Accidents}

With the sudden increase of frequency of road traffic accidents all over the world it is now considered as a growing problem that threatens the lives of many people all over the globe. According to the World Health Organization, road traffic accidents cause the death of more than 1.2 million and the injury of between 20 and 50 million people annually worldwide with more than $90 \%$ of deaths in low and middle income countries. (Ismail \& Abdelmageed, 2010). Traffic accidents are dependent events. In general, accidents are defined by a series of variables that helps to analyze traffic accident and to identify 
significant factors that affect injury severity (de Oña, López, Mujalli, \& Calvo, 2013).

Despite continuous improvements in vehicle technology and road engineering, road accidents is still one of the major accidental causes of death and injury. (WHO, 2004). Traffic accidents is an important issues in the world and both the location and frequency of traffic accidents are subject to changes as time passed, and these accidents can be measured as discrete random, which represents a low occurrence probability (Soler-Flores, 2013).

The concern with road accidents has become global and an important social issue. According to a study made in Britain, there were 7000 deaths and injuries recorded each year which usually occurs among cyclists and pedestrians. (Bartrip, 2010). The National Highway Traffic Safety Administration of the United States of America report, states that the fatality rate per 100 million vehicle miles traveled has reached the lowest point of 1.10 in 2010 while the injury rate per 100 million VMT is the same as those of 2009. ("Research Note 2010 Motor Vehicle Crashes: Overview," 2012). In China, an average of one person died in every four reported traffic crashes. Also, Urban Roads in China had alarmingly higher rates of crashes in China. They are situated in urban areas where traffic volume is high and road traffic conditions are particularly complicated (Loo, Cheung, \& Yao, 2011).

\subsection{Accident Factors}

Analysis of crash data that are collected through police reports and integrated with road inventory data reveals important relationships that can help focus on high-risk situations and coming up with safety countermeasures (Dong, Clarke, Yan, Khattak, \& Huang, 2014). The factors contributing to road site accidents are age, alcohol intake, gender, vehicle speed, whether seatbelts were used, whether the driver was ejected from the vehicle, whether the crash was a head-on collision, whether an airbag was deployed, and whether one of the vehicles was following too close behind another vehicle (Zhang, 2010). The study in USA shows that drivers' adaptation to weather conditions influence the changes in roadway-surface conditions and results injury severity that influenced by many factors, including age and gender (Morgan \& Mannering, 2011).

Human factor remains the leading cause of road traffic accidents, such as over speeding, carelessness and fatigue (Khan, Al Asiri, \& Iqbal, 2010). A study has concluded that there is a significant potential human behavioral contribution to pedestrian injury at the study sites (Cinnamon, Schuurman, \& 
Hameed, 2011). Road transport is definitely a huge benefit to our society, but it also has problem such as delays because of traffic congestion and transport accidents (Quddus, 2008).

\subsection{Markov Chain Switching Approach}

Markov-switching models of severity have the advantage to obtain unobserved heterogeneity in accident data that could relate to different weather conditions and other different factors that may not be known to the analyst (Malyshkina \& Mannering, 2009). Some other study shows how incidents are very notorious for their delays to road users. Heterogeneity models such as Markov switching random parameters models give a promising method to decompose unobserved heterogeneity for an ordered or unordered discrete result data analysis (Xiong, Tobias, \& Mannering, 2014).

There are other studies of determining road accidents frequency. A Bayesian network used to estimate a frequency which is applicable in any situation and any set of data that is available (Soler-flores, 2013). Other model use in determining crash frequency is multivariate model. It is a useful method for analysis since it account accounts the correlation among specific crash types (Dong, Richards, Clarke, Zhou, \& Ma, 2014).

A study is conducted in Arkansas to evaluate the intersection accidents using traffic safety analysis methods. In 2004, Arkansas was the top three in the states with highest traffic fatalities. A statistical approach was made using Poisson, Negative Binomial and Logistics Regression Model. The study considered significant contributors namely road width, number of lanes, pavement condition, horizontal and vertical curvature of the road design. The result of the study gave a highlight to the potential issues of the driver behaviors and roadway characteristics that affect road traffic safety (Nam \& Song, 2008).

\section{Methodology}

The study used Qualitative and Quantitative research methods. A qualitative research method was used for data gathered through observations and interviews of the different traffic regulating personnel, organizations and offices and gain familiarity of the different road traffic accidents occurring along Commonwealth Avenue as well as the nature of the road stretch and its other features.

The quantitative research method was used to determine the relationship between the factors affecting the occurrence of a crash accident and the severity 
of an accident. The hypothesis is provable by mathematical and statistical means further supporting the use of quantitative research design. This is also a descriptive study since it involved collecting data on a changing environment where no manipulation of the different factors was done.

The sampling design used is purposive or judgmental sampling, a nonprobability sampling technique where researchers selected units to be sampled based on their knowledge and professional judgment (Castillo, 2009). The sample data had undergone a selection process where each entry was evaluated for compliance with the requirements set for completeness of data entry.

The Markov Switching Approach Analysis was used to determine the factors that are significant to the severity of road traffic accidents along Commonwealth Avenue. The Multinomial Logistics Regression was used to analyze the factors that are found significant with the severity. From the factors that are found significant to severity, these were further analyzed for test of significance to the different levels of severity. Furthermore, the different critical driver errors in the occurrence of road traffic accidents were tested for significance to each level of severity of accident.

Ten independent variables that were considered in the study of road traffic accidents along Commonwealth Avenue. These are 1) time, 2) month occurred; 3) type of junction, 4) type of junction control, 5) darkness indication, 6) weather, 7) type of collision, 8) accident factor, 9) age, and 10) gender.

The dependent variable is the level of severity which is classified into three levels: 1) fatal injury, 2) non-fatal injury and 3) no injury.

\section{Data and Results}

A total of 11,894 road traffic accidents recorded from 2009 to March of 2013 were initially considered. Using a selection process that requires completeness of data entry, this was reduced to 2,029 data samples which were eventually used in the study. Data with incomplete entry details were excluded.

\subsection{Markov Chain Switching Approach}

Markov Chain Switching model allows to tests for the significance of a variable to the severity level with respect to different time-varying constraints. Through this method, the significant variables of severity of road traffic accidents are extracted. The probability of occurrence and expected duration for the significant predictor variables are also identified and interpreted. The test for significance is performed at a $95 \%$ level of significance. Shown in Table 1 is 
Table 1 Markov chain switching approach test for significance $(\mathrm{CI}=95 \%)$

\begin{tabular}{|c|c|c|c|c|c|c|}
\hline \multirow[b]{2}{*}{ Variable } & \multicolumn{2}{|c|}{$\begin{array}{l}\text { Probability } \\
\text { of Occurrence }\end{array}$} & \multicolumn{2}{|c|}{$\begin{array}{l}\text { Expected Duration } \\
\text { (Months) }\end{array}$} & \multicolumn{2}{|c|}{ Standard Error } \\
\hline & Regime 1 & Regime 2 & Regime 1 & Regime 2 & Regime 1 & Regime 2 \\
\hline Accident Factor & $66.6016 \%$ & $99.9014 \%$ & 2.99 & 1013.98 & 0.002706 & 0.000063 \\
\hline Age Indicator & $95.1478 \%$ & $99.9013 \%$ & 20.61 & 1013.59 & 0.003937 & 0.000116 \\
\hline Collision Type & $76.2777 \%$ & $99.9271 \%$ & 4.22 & 1372.02 & 0.003871 & 0.002274 \\
\hline Darkness Indicator & $0.00630 \%$ & $99.8518 \%$ & 1.00 & 674.58 & 0.00539 & 0.167800 \\
\hline Month & $71.3337 \%$ & $99.6336 \%$ & 3.49 & 272.93 & 0.001855 & 0.026200 \\
\hline Gender & $97.7917 \%$ & $79.3084 \%$ & 45.28 & 4.83 & 0.001286 & 0.026085 \\
\hline Junction Control & $98.0600 \%$ & $99.9013 \%$ & 51.55 & 1013.08 & 0.002860 & 0.000979 \\
\hline Junction Type & $62.9393 \%$ & $50.7012 \%$ & 2.70 & 2.03 & 0.019000 & 0.025900 \\
\hline Time & $0.06250 \%$ & $99.8520 \%$ & 1.00 & 675.73 & 0.005423 & 0.417100 \\
\hline Weather & $99.9014 \%$ & $0.0002 \%$ & 1013.87 & 1.00 & 0.028600 & 0.007286 \\
\hline
\end{tabular}

the 10 variables available for testing. These variables are demographic and accident-related in nature. The results that were gathered from computing Markov Switching Approach from the different factors, the factors that have a significant effect with the severity (Fatal, Non-Fatal, No Injury) of road accidents in Commonwealth Avenue were able to distinguish with its behavior with respect to their values based both from regimes 1 and regime 2 .

As what can be seen in the table, the factors that have probabilities that the level of severity is dependent are: Accident Factor, Age Indicator, Collision Type, Month, Gender, Junction Control, Junction Type, and Weather. While factors: Darkness Indication, and Time have probabilities that the level of severity is independent.

\subsection{Multinomial Logistic Regression Analysis for Testing the Significant Factors Per Level of Severity}

Multinomial Logistic Regression enables to test for the significance of the significant factors gathered from the Markov Chain Switching approach with respect to the three severity level (Fatal, Non-Fatal, and No Injury) that are observed in every road traffic accident. The data result in the table below shows the results. The regression analysis was computed at $95 \%$ level of significance.

Illustrated on Table 2 is the results gathered from the IBM SPSS Statistics software and using both the B coefficient and odds ratio, $\operatorname{Exp}(B)$ as a basis if can be assumed that for fatal injuries the significant factors are the Accident factor with a B coefficient of greater than zero $(0.547>0)$ and an odds ratio of greater than one $(1.727>1)$; Month with a $\mathrm{B}$ coefficient of greater than zero 
Table 2 Multinomial logistic regression analysis test for significance for accidents with fatal injuries $(\mathrm{CI}=95 \%)$

\begin{tabular}{lcccc}
\hline & & & \multicolumn{2}{c}{$95 \%$ C.I. for Exp(B) } \\
\cline { 4 - 5 } Severity & $\mathrm{B}$ & $\operatorname{Exp}(\mathrm{B})$ & Lower Bound & Upper Bound \\
\hline Intercept & 17.849 & & & \\
Accident_Factor & .547 & 1.727 & .364 & 8.199 \\
Age_Indicator & -13.915 & $9.053 \mathrm{E}-07$ & $4.361 \mathrm{E}-07$ & $1.879 \mathrm{E}-06$ \\
Collision_Type & -.423 & .655 & .356 & 1.207 \\
Gender & 13.836 & 1020575.781 & 0.000 & 2943024.102 \\
Junction_Control & .267 & 1.307 & .070 & 24.404 \\
Junction_Type & .454 & 1.574 & .741 & 3.343 \\
Month & .092 & 1.096 & .639 & 1.881 \\
Weather & -2.371 & .093 & .004 & 2.304 \\
\hline
\end{tabular}

$(0.092>0)$ and an odds ratio of greater than one $(1.096>1)$; Gender with a $B$ coefficient of greater than zero $(13.836>0)$ and an odds ratio of greater than one $(2943024.102>1)$; Type of Junction with a B coefficient of greater than zero $(0.454>0)$ and an odds ratio of greater than one $(3.343>1)$; and Type of Junction control with a B coefficient of greater than zero $(0.267>0)$ and an odds ratio of greater than one $(1.307>1)$.

Illustrated on Table 3 is the results gathered from the IBM SPSS Statistics software and using both the $\mathrm{B}$ coefficient and odds ratio, $\operatorname{Exp}(\mathrm{B})$ as a basis if can be assumed that for non-fatal injuries the significant factors are the Accident factor with a B coefficient of greater than zero $(0.425>0)$ and an odds ratio of greater than one $(1.529>1)$; Month with a B coefficient of greater than zero $(0.132>0)$ and an odds ratio of greater than one $(1.141>1)$; Gender with a B coefficient of greater than zero $(14.215>0)$ and

Table 3 Multinomial logistic regression analysis test for significance for accidents with nonfatal injuries $(\mathrm{CI}=95 \%)$

\begin{tabular}{lcccc}
\hline & & & \multicolumn{2}{c}{$95 \%$ C.I. for Exp(B) } \\
\cline { 4 - 5 } Severity & $\mathrm{B}$ & $\operatorname{Exp}(\mathrm{B})$ & Lower Bound & Upper Bound \\
\hline Intercept & 19.575 & & & \\
Accident_Factor & .425 & 1.529 & .331 & 7.069 \\
Age_Indicator & -13.715 & $1.106 \mathrm{E}-06$ & $1.106 \mathrm{E}-06$ & $1.106 \mathrm{E}-06$ \\
Collision_Type & -.271 & .763 & .418 & 1.392 \\
Junction_Control & .455 & 1.576 & .089 & 27.898 \\
Junction_Type & .517 & 1.677 & .798 & 3.523 \\
Month & .132 & 1.141 & .669 & 1.946 \\
Weather & -2.111 & .121 & .005 & 2.818 \\
Gender & 14.215 & 1491077.823 & 0.000 & 1735352.149 \\
\hline
\end{tabular}


Table 4 Multinomial logistic regression analysis test for significance for accidents with no injuries $(\mathrm{CI}=95 \%)$

\begin{tabular}{lcccc}
\hline & & & \multicolumn{2}{c}{$95 \%$ C.I. for $\operatorname{Exp}(\mathrm{B})$} \\
\cline { 4 - 5 } Severity & $\mathrm{B}$ & $\operatorname{Exp}(\mathrm{B})$ & Lower Bound & Upper Bound \\
\hline Intercept & -20.848 & & & \\
Accident_Factor & -.547 & .579 & .122 & 2.748 \\
Age_Indicator & 16.915 & 22175601.732 & 22175601.732 & 22175601.732 \\
Collision_Type & .423 & 1.526 & .828 & 2.810 \\
Gender & -16.835 & $4.883 \mathrm{E}-08$ & 0.000 & 3.124 \\
Junction_Control & -.267 & .765 & .041 & 14.296 \\
Junction_Type & -.454 & .635 & .299 & 1.349 \\
Month & -.092 & .912 & .532 & 1.564 \\
Weather & 2.371 & 10.709 & .434 & 264.295 \\
\hline
\end{tabular}

an odds ratio of greater than one (1491077.823 > 1); Type of Junction with a $\mathrm{B}$ coefficient of greater than zero $(0.517>0)$ and an odds ratio of greater than one $(1.667>1)$; and Type of Junction control with a B coefficient of greater than zero $(0.455>0)$ and an odds ratio of greater than one $(1.576>1)$.

Illustrated on Table 4 is the results gathered from the IBM SPSS Statistics software and using both the $\mathrm{B}$ coefficient and odds ratio, $\operatorname{Exp}(\mathrm{B})$ as a basis if can be assumed that for no injury the significant factors are Collision Type with a $B$ coefficient of greater than zero $(0.423>0)$ and an odds ratio of greater than one $(1.526>1)$; Age Indicator with a B coefficient of greater than zero $(16.915>0)$ and an odds ratio of greater than one $(22175601.732>1)$; Weather with a B coefficient of greater than zero $(2.371>0)$ and an odds ratio of greater than one $(10.709>1)$.

\subsection{Multinomial Logistic Regression Analysis for Testing the Significant Factors Per Critical Driver Errors}

Human error has been one of the major contributor of the occurrence of an accident, the proponent was able to draw 14 driver errors which were based on the most usual errors that were committed that can be observed from the entire road stretch and based from the data that came from the Metropolitan Manila Development Authority (MMDA). These human errors that are usually committed are: Alcohol Suspected; Avoided Hitting Other Vehicle, Buildings and Etc.; Avoided Hitting Pedestrian; Lost Control; Moving Backward/Backing Inattentively; Sudden Stop; Slept; Bad Turn; Driver Error; Miscalculated Movement; Lost Balance; Inattentive/Too Fast; Bad Overtaking; and Disobey Traffic Lights/Signs. 
The result from the performed statistical test is illustrated in Table 5. Based on the results gathered from the IBM SPSS Statistics software and using both the B coefficient and odds ratio, $\operatorname{Exp}(B)$ as a basis if can be assumed that for fatal injury the critical driver errors are: Alcohol Suspected with a B coefficient of greater than zero $(15.952>0)$ and an odds ratio of greater than one (8466730.558 > 1); Avoided Hitting Other Vehicle, Buildings And Etc. with a B coefficient of greater than zero $(0.385>0)$ and an odds ratio of greater than one $(1.469>1)$; Lost Control with a B coefficient of greater than zero $(15.615>0)$ and an odds ratio of greater than one $(6047664.724>1)$; Sudden Stop with a B coefficient of greater than zero $(14.557>0)$ and an odds ratio of greater than one (2099189.395 > 1); Driver Error with a B coefficient of greater than zero $(.388>0)$ and an odds ratio of greater than one $(1.473>1)$; Lost Balance with a B coefficient of greater than zero $(14.557>0)$ and an odds ratio of greater than one (2099189.395 > 1); and Inattentive/Too Fast with a B coefficient of greater than zero $(15.158>0)$ and an odds ratio of greater than one $(3829174.649>1)$.

Based from the results illustrated in Table 6 that were gathered from the IBM SPSS Statistics software and using both the B coefficient and odds ratio, $\operatorname{Exp}(B)$ as a basis if can be assumed that for fatal injury the critical driver errors are: Alcohol Suspected with a B coefficient of greater than zero $(1.281>0)$ and an odds ratio of greater than one $(3.600>1)$; Avoided Hitting Other Vehicle, Buildings And Etc. with a B coefficient of greater than zero (1.099>0)

Table 5 Multinomial logistic regression analysis test for significance for human factors relative to fatal injuries $(\mathrm{CI}=95 \%)$

\begin{tabular}{lrrr}
\hline Injury_Severity & \multicolumn{1}{c}{$\mathrm{B}$} & $\mathrm{df}$ & \multicolumn{1}{c}{$\operatorname{Exp}(\mathrm{B})$} \\
\hline Intercept & -18.254 & 1 & \\
Alcohol Suspected & 15.952 & 1 & 8466730.613 \\
Avoided Hitting Other Vehicle, Buildings And Etc. & .385 & 1 & 1.469 \\
Avoided Hitting Pedestrian & -.121 & 1 & .886 \\
Lost Control & 15.615 & 1 & 6047664.724 \\
Moving Backward/Backing Inattentively & -.155 & 1 & .856 \\
Sudden Stop & 14.557 & 1 & 2099189.408 \\
Slept & -.380 & 1 & .684 \\
Bad Turn & -.210 & 1 & .810 \\
Driver Error & .388 & 1 & 1.473 \\
Miscalculated Movement & -.380 & 1 & .684 \\
Lost Balance & 14.557 & 1 & 2099189.408 \\
Inattentive/Too Fast & 15.158 & 1 & 3829174.649 \\
Bad Overtaking & -.199 & 1 & .820 \\
Disobey Traffic Lights/Signs & -0.456 & 1 & 0.84 \\
\hline
\end{tabular}


Table 6 Multinomial logistic regression analysis test for significance for human factors relative to non-fatal injuries $(\mathrm{CI}=95 \%)$

\begin{tabular}{lrrr}
\hline Injury_Severity & \multicolumn{1}{c}{$\mathrm{B}$} & $\mathrm{df}$ & \multicolumn{1}{c}{$\operatorname{Exp}(\mathrm{B})$} \\
\hline Intercept & -1.792 & 1 & \\
Alcohol Suspected & 1.281 & 1 & 3.600 \\
Avoided Hitting Other Vehicle, Buildings And Etc. & 1.099 & 1 & 3.000 \\
Avoided Hitting Pedestrian & -.511 & 1 & .600 \\
Lost Control & 1.827 & 1 & 6.214 \\
Moving Backward/Backing Inattentively & -.693 & 1 & .500 \\
Sudden Stop & 17.078 & 1 & 26110021.061 \\
Slept & -13.478 & 1 & $1.402 \mathrm{E}-06$ \\
Bad Turn & -1.041 & 1 & .353 \\
Driver Error & 1.106 & 1 & 3.021 \\
Miscalculated Movement & -13.478 & 1 & $1.402 \mathrm{E}-06$ \\
Lost Balance & 17.078 & 1 & 26110021.061 \\
Inattentive/Too Fast & 1.910 & 1 & 6.754 \\
Bad Overtaking & -.960 & 1 & .383 \\
Disobey Traffic Lights/Signs & -.856 & 1 & .215 \\
\hline
\end{tabular}

and an odds ratio of greater than one $(3.000>1)$; Lost Control with a B coefficient of greater than zero $(1.827>0)$ and an odds ratio of greater than one (6.214> 1); Sudden Stop with a B coefficient of greater than zero $(14.557>0)$ and an odds ratio of greater than one $(26110021.061>1)$; Driver Error with a B coefficient of greater than zero $(1.106>0)$ and an odds ratio of greater than one $(3.021>1)$; Lost Balance with a B coefficient of greater than zero $(17.078>0)$ and an odds ratio of greater than one $(26110021.061>1)$; and Inattentive/Too Fast with a B coefficient of greater than zero $(1.910>0)$ and an odds ratio of greater than one $(6.754>1)$.

Illustrated in Table 7 is the results that were gathered from the IBM SPSS Statistics software and using both the B coefficient and odds ratio, $\operatorname{Exp}(B)$ as a basis if can be assumed that for fatal injury the critical driver errors are: Avoided Hitting Pedestrian with a B coefficient of greater than zero $(.121>0)$ and an odds ratio of greater than one (1.129 > 1); Moving Backward/Backing Inattentively with a B coefficient of greater than zero $(.155>0)$ and an odds ratio of greater than one $(1.168>1)$; Slept with a $\mathrm{B}$ coefficient of greater than zero $(.380>0)$ and an odds ratio of greater than one $(1.462>1)$; Bad Turn with a $\mathrm{B}$ coefficient of greater than zero $(.210>0)$ and an odds ratio of greater than one (1.234>1); Miscalculated Movement with a B coefficient of greater than zero $(.380>0)$ and an odds ratio of greater than one $(1.462>1)$; Bad Overtaking with a B coefficient of greater than zero $(.199>0)$ and an odds ratio of greater than one $(1.220>1)$; and Disobey Traffic Lights/Signs with a 
Table 7 Multinomial logistic regression analysis test for significance for human factors relative to no injuries $(\mathrm{CI}=95 \%)$

\begin{tabular}{lrrr}
\hline Injury_Severity & \multicolumn{1}{c}{ B } & df & Exp(B) \\
\hline Intercept & 18.254 & 1 & \\
Alcohol Suspected & -15.952 & 1 & $1.181 \mathrm{E}-07$ \\
Avoided Hitting Other Vehicle, Buildings And Etc. & -.385 & 1 & .681 \\
Avoided Hitting Pedestrian & .121 & 1 & 1.129 \\
Lost Control & -15.615 & 1 & $1.654 \mathrm{E}-07$ \\
Moving Backward/Backing Inattentively & .155 & 1 & 1.168 \\
Sudden Stop & -14.557 & 1 & $4.764 \mathrm{E}-07$ \\
Slept & .380 & 1 & 1.462 \\
Bad Turn & .210 & 1 & 1.234 \\
Driver Error & -.388 & 1 & .679 \\
Miscalculated Movement & .380 & 1 & 1.462 \\
Lost Balance & -14.557 & 1 & $4.764 \mathrm{E}-07$ \\
Innatentive/Too Fast & -15.158 & 1 & $2.612 \mathrm{E}-07$ \\
Bad Overtaking & .199 & 1 & 1.220 \\
Disobey Traffic Lights/Signs & 0.158 & 1 & 1.112 \\
\hline
\end{tabular}

B coefficient of greater than zero $(.158>0)$ and an odds ratio of greater than one $(1.112>1)$.

\section{Conclusion}

The study considered 10 factors as independent variables. These are time, month, type of junction, type of junction control, darkness indication, weather, type of collision, accident factor, age, and gender, related to the different road traffic accidents that occurred along Commonwealth Avenue. The dependent variable is the level of severity which is classified into three (3) levels as fatal injury, non-fatal injury and no injury.

Applying Markov Chain Switching Approach, it was determined that 8 out of the 10 factors have significant effect to the severity of road traffic accidents. These are accident factor, age indicator, collision type, month, gender, junction control, junction type, and weather. The values of B coefficient and odds ratio were used in identifying the significance of the variables which both showed parallel results.

The eight significant variables obtained p-values that are less than 0.05 , testing for a 5\% level of significance. This implies that the null hypothesis of no significance to severity of crash injury accident is rejected. Hence, these variables are significant with respect to the severity of road traffic accidents. 
The eight significant variables to severity of road traffic accidents were further tested to determine which among these factors are relevant to the three levels of severity, i.e., fatal, non-fatal and no injury. The multinomial logistic regression method was used since this allows the analysis of categorical and quantitative variables simultaneously.

Among the eight factors that are found significant to severity of road traffic accidents, five of these were found significant relative to the occurrence of road traffic accidents resulting to fatal and non-fatal injuries and these are, accident factor, gender, month, type of junction, and the type of junction control. For the occurrence of road traffic accidents that could result into No injury, the factors that were found significant are age, type of collision, and weather.

The multinomial logistic regression method was used to test which among the human errors are significant with the three levels of severity of injury, i.e., fatal, non-fatal and no injury. This statistical test was used since all of the variables are in categorical form hence; it is an appropriate test to determine the relationship of the variables.

Seven human errors were found to be significant with the probability of road traffic accidents with fatal and non-fatal injuries, and these are: 1) Alcohol Suspected; 2) Avoided Hitting Other Vehicle, Buildings and others.; 3) Lost Control; 4) Sudden Stop; 5) Driver Error; 6) Lost Balance; and 7) Inattentive/Too Fast.

Also, seven factors that were found significant with the probability of road traffic accidents with no injury and these are: 1) avoided hitting pedestrian; 2) moving backward/backing inattentively; 3) miscalculated movement; 4) slept; 5) bad turn; 6) bad overtaking; and 7) disobey traffic lights/signs.

\section{References}

[1] Anastasopoulos, P. C., Mannering, F. L., Shankar, V. N., and Haddock, J. E. (2012). A study of factors affecting highway accident rates using the random-parameters tobit model. Accid. Anal. Prevent. 45, 628-33. doi:10.1016/j.aap.2011.09.015

[2] Anastasopoulos, P. C., Shankar, V. N., Haddock, J. E., and Mannering, F. L. (2012). A multivariate tobit analysis of highway accident-injury-severity rates. Accid. Anal. Prevent. 45, 110-9. doi:10.1016/j.aap.2011.11.006

[3] Authority, R. S. (2008). Road Collision Facts 2008. Ireland: Road Safety Authority. 
[4] Bazzi, M., Blasques, F., Koopman, S. J., and Lucas, A. (2014). Time Varying Transition Probabilities for Markov Regime Switching Models. Tinbergen Institute Discussion Paper, The Netherlands.

[5] Castro, M., Paleti, R., and Bhat, C. R. (2013). A spatial generalized ordered response model to examine highway crash injury severity. Accid. Anal. Prevent. 52, 188-203. doi:10.1016/j.aap.2012.12.009

[6] De Oña, J., López, G., Mujalli, R., and Calvo, F. J. (2013). Analysis of traffic accidents on rural highways using Latent Class Clustering and Bayesian Networks. Accid. Anal. Prevent. 51, 1-10. doi:10.1016/j. aap.2012.10.016

[7] Dong, C., Clarke, D. B., Yan, X., Khattak, A., and Huang, B. (2014). Multivariate random-parameters zero-inflated negative binomial regression model: an application to estimate crash frequencies at intersections. Accid. Anal. Prevent. 70, 320-9. doi:10.1016/j.aap.2014.04.018

[8] Dong, C., Richards, S. H., Clarke, D. B., Zhou, X., and Ma, Z. (2014). Examining signalized intersection crash frequency using multivariate zero-inflated Poisson regression. Safety Sci. 70, 63-69. doi:10.1016/j.ssci.2014.05.006

[9] Grinstead, C. M., and Snell, J. L. (2010). "Markov chains". Introduction to Probability, 3rd Edn, 1-66.

[10] E Views® 8. (n.d.) EViews 8.1 User's Guide II. Irvine, CA: IHS Global Inc.

[11] Jung, S., Jang, K., Yoon, Y., and Kang, S. (2014). Contributing factors to vehicle to vehicle crash frequency and severity under rainfall. J. Safety Res. 50, 1-10. doi:10.1016/j.jsr.2014.01.001

[12] Kwak, C., and Clayton-Matthews, A. (2005). Multinomial logistic regression. Nursing Res. 51, 404-410. doi:10.1097/00006199-20021100000009

[13] Libres, G. T. E. D. C., Galvez, M. A. L. I., Cordero, C. J. N., and Program, B. S. C. E. (2008). Analysis of Relationship between Driver Characteristic and Road Accidents along Commonwealth Avenue, 1-5. CE 198 - Undergraduate Research Program in Civil Engineering, University of the Philippines Diliman, Quezon City, PHP.

[14] Maata, H. E. (2013). "Assessment of Vehicle Speeds and Traffic Safety along Commonwealth Avenue", in 21st Annual Conference of the Transportation Science Society of the Philippines, Cebu City, PHP, 9 Aug 2013.

[15] Malyshkina, N. V, and Mannering, F. L. (2009). Markov switching multinomial logit model: An application to accident-injury severities. Accid. Anal. Prevent. 41(4), 829-38. doi:10.1016/j.aap.2009.04.006 
[16] Malyshkina, N. V, and Mannering, F. L. (2010a). Empirical assessment of the impact of highway design exceptions on the frequency and severity of vehicle accidents. Accid. Anal. Prevent. 42(1), 131-9. doi:10.1016/j.aap.2009.0 7.013

[17] Malyshkina, N. V, and Mannering, F. L. (2010b). Zero-state Markov switching count-data models: an empirical assessment. Accid. Anal. Prevent. 42(1), 122-30. doi:10.1016/j.aap.2009.07.012

[18] Malyshkina, N. V, Mannering, F. L., and Tarko, A. P. (2009). Markov switching negative binomial models: an application to vehicle accident frequencies. Accid. Anal. Prevent. 41(2), 217-226. doi:10.1016/ j.aap.2008.11.001

[19] Morgan, A., and Mannering, F. L. (2011). The effects of road-surface conditions, age, and gender on driver-injury severities. Accid. Anal. Prevent. 43(5), 1852-63. doi:10.1016/j.aap.2011.04.024

[20] IDRE Statistical consulting group. (n.d.). Multinomial Logistic Regression Models., 1-20. Institute for Digital Research and education.

[21] Ng, M., Khattak, A., and Talley, W. K. (2013). Modeling the time to the next primary and secondary incident: a semi-Markov stochastic process approach. Transport. Res. B Method. 58, 44-57. doi:10.1016/j.trb.2013.09.013

[22] Noland, R. B., Klein, N. J., and Tulach, N. K. (2013). Do lower income areas have more pedestrian casualties? Accid. Anal. Prevent. 59, 337-45. doi:10.1016/j.aap.2013.06.009

[23] Norman, L. G. (1962). Road traffic accidents: epidemiology, control, and prevention. World Health Organisation. Retrieved from http://extranet.who.int/iris/handle/10665/39723

[24] Paul, S. (1969). E Views, 151, p. 4733.

[25] Quddus, M. a. (2008). Time series count data models: an empirical application to traffic accidents. Accid. Anal. Prevent. 40(5), 1732-41. doi:10.1016/j.aap.2008.06.011

[26] Research Note 2010 Motor Vehicle Crashes?: Overview. (2012), (February).

[27] Savolainen, P. T., Mannering, F. L., Lord, D., and Quddus, M. a. (2011). The statistical analysis of highway crash-injury severities: A review and assessment of methodological alternatives. Accid. Anal. Prevent. 43, 1666-1676. doi:10.1016/j.aap.2011.03.025

[28] Soler-flores, F. (2013). "Expert system for road accidents frequency estimation based in Naïve-Poisson," in Proceedings In Gv - Global Virtual Conference, EDIS - Publishing Institution of the University of Zilina, Žilina, 646-651. 
[29] Soler-Flores, F. (2013). Naïve-Poisson, a mathematical model for road accidents frequency estimation., 384-91. Retrieved from http://www. ictic.sk/archive/?vid=1\&aid=2\&kid=50201-59

[30] Wang, C., Quddus, M. a, and Ison, S. G. (2009). Impact of traffic congestion on road accidents: a spatial analysis of the M25 motorway in England. Accid. Anal. Prevent. 41(4), 798-808. doi:10.1016/j.aap.2009.04.002

[31] Weber, R. (2012). Markov Chains, 1-57. doi:10.1017/CCOL052153428 3.010

[32] WHO. (2004). Global Status Report on Road Safety. GLOBAL STATUS REPORT.

[33] Xie, K., Wang, X., Ozbay, K., and Yang, H. (2014). Crash frequency modeling for signalized intersections in a high-density urban road network. Anal. Method Accid. Res. 2, 39-51. doi:10.1016/j.amar.2014.06.001

[34] Xiong, Y., Tobias, J. L., and Mannering, F. L. (2014). The analysis of vehicle crash injury-severity data: A Markov switching approach with road-segment heterogeneity. Transport. Res. B Method. 67, 109-28. doi:10.1016/j.trb.2014.04.007

[35] Yu, R., and Abdel-Aty, M. (2014). Using hierarchical Bayesian binary probit models to analyze crash injury severity on high speed facilities with real-time traffic data. Accid. Anal. Prevent. 62, 161-7. doi:10.1016/j.aap.2013.08.009

[36] Zelen, M. (1991). Multinomial response models. Comput. Stat. Data Anal. 12, 249-54. doi:10.1016/0167-9473(91)90023-U

[37] Zeng, Q., and Huang, H. (2014). Bayesian spatial joint modeling of traffic crashes on an urban road network. Accid. Anal. Prevent. 67, 105-12. doi:10.1016/j.aap.2014.02.018

\section{Biographies}

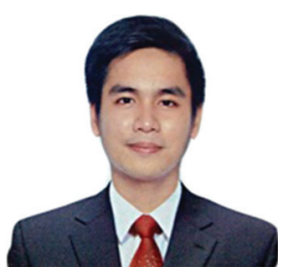

J. C. F. Marquez is a B.S. Industrial Engineering degree holder from Adamson University, Manila, Philippines. Currently, he serves as a Logistics Associate in one of the biggest food-logistics firm in the Philippines. 


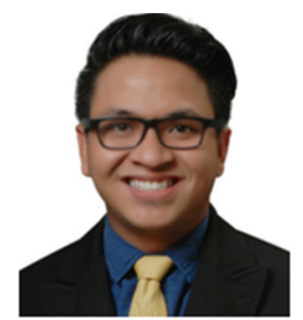

D. J. B. Ronquillo received his B.S. Industrial Engineering degree from Adamson University, Manila, Philippines in 2015. He is currently involved in the Continuous Quality Improvement and Outcomes-based Education System of the same institution.

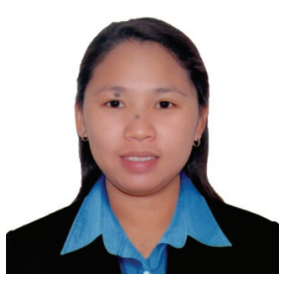

N. B. Fernandez is a graduate of B.S. Industrial Engineering from Adamson University, Manila, Philippines. She serves as a college instructor at the same institution handling Probability and Statistics, Engineering Economy and Materials and Processes Courses.

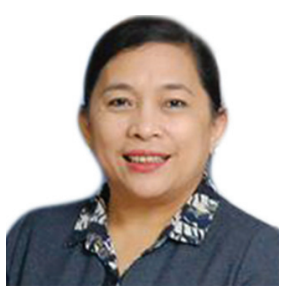

V. C. Quevedo earned her Ph.D. Degree in Educational Evaluation and Research and M.S. in Industrial Engineering Major in Operations Research at the University of the Philippines - Diliman. She serves as the Vice President for Administrative Affairs and an Associate Professor of the Industrial Engineering Department of Adamson University. 